\title{
APRENDER A VIVIR. EXISTENCIA, PENSAMIENTO, HUELLA EN/DE DERRIDA
}

\author{
DOMINGO FERNÁNDEZ AGIS \\ Universidad de La Lagura
}

\begin{abstract}
RESUMEN: En este trabajo abordo el problema de la herencia nietzscheana en el pensamiento de Jacques Derrida como base para plantear la cuestión de la huella de éste último en la filosofía actual. Para ello, me aproximo a la relación entre vida e ideal de vida, tal como la pensaron ambos. Partiendo de este aspecto, planteo el problema de la relación entre vida y obra, la cuestión de la identidad personal, la valoración del pensamiento como actividad crítica y la cuestión de la posibilidad de lo imposible, que resulta central en el pensamiento derridiano. A través de todo ello, pretendo poner de manifiesto la enorme proyección de futuro que a mi juicio tiene la obra de Derrida.
\end{abstract}

PALABRAS CLAVE: vida; obra; identidad; pensamiento crítico; posibilidad de lo imposible; Derrida; Nietzsche.

\section{Learn to live \\ Existence, thought, trace in / of Derrida.}

ABSTRACT: In this paper I approach the problem of the Nietzschean heritage in the thought of Jacques Derrida as a basis for raising the question of the footprint of the latter in current philosophy. For this, I approach the relationship between life and ideal of life, as both thought. Starting from this aspect, I pose the problem of the relationship between life and work, the question of personal identity, the assessment of thought as a critical activity and the question of the possibility of the impossible, which is central to Derridian thought. Through all this, I intend to highlight the enormous future projection that in my opinion Derrida's work has.

KEY WORDS: life; work, identity; critical thinking; possibility of the impossible; Derrida; Nietzsche.

Tienes en la cabeza un ideal noble: pero ¿eres tú un mármol noble, digno de que se labre en él la estatua de un dios? Y si no es así - ¿no es todo tu trabajo esculpir bárbaro? ¿Un ultraje a tu ideal?

Nietzsche, F., La gaya ciencia, § 215

\section{INTRODUCCIÓN}

¿Refiriéndonos a quién, diríamos que estuvo a la altura de su ideal? ¿Lo estuvo Derrida al perseguir en su vida la materialización del ideal nietzscheano de pensar contra todo y contra todos? ¿Lo estuvo el propio autor de Así habló Zaratustra? Ni a él ni a nadie le deberíamos reprochar no haberlo logrado. Quizá no sea el logro del ideal lo más digno de elogio, tal vez lo sea mucho más hacer algo digno con la experiencia continuada de la imposibilidad de realizarlo.

Por lo demás, Nietzsche propone dos ideas que son muy difíciles de asumir: el eterno retorno y el rechazo de la compasión. No las hizo suyas Jacques 
Derrida y esa es una de las razones por las que muchos de sus lectores nos podemos sentir en sintonía con él y así hallar en sus ideas algo que podríamos considerar como un cierto soporte vital. El primero de tales conceptos es aceptable como fundamento de una moral sin imperativos ni códigos externos a la propia acción. En efecto, si uno actúa pensando si le importaría o no que lo que hace se repita un millón de veces, no necesita apelar a un código que le señale el modo de diferenciar qué es el bien y qué el mal. No obstante, cuando pasamos desde ahí al plano ontológico, en su doble dimensión de materialidad e institucionalidad, la posibilidad de la repetición indefinida de lo mismo sería la negación de la libertad y, por tanto, la imposibilidad de una vida humana en la plenitud del sentido de ese término. Por otra parte, si no se le da un sentido cósmico a la idea del eterno retorno, sería más fácil aceptarla pues las emociones humanas, las pasiones, los dolores y las alegrías, se van a repetir a lo largo de la vida. Pero si lo que nos intenta decir es que vamos a estar una y otra vez ante las mismas situaciones, la vida humana se convierte en un tiovivo, pues nuestra mayor aspiración se convertiría en algo decididamente menor, ya que se reduciría a aprender a subir y bajar con elegancia del caballo de madera lacada; cosa, por lo demás, harto difícil, dada la ausencia de nobleza del pobre animal empalado y la manifiesta cobardía de quien sube y baja de él pues no se atreve a montar a lomos de un equino real.

Además de ello, y por grande que sea la dosis de anticristianismo que Nietzsche ponga sobre la mesa para justificarse, no creo que sea posible una moral humana sin compasión. Ya se sabe que él habla de una moral sobrehumana, de una moral de superhombres. Pero si el superhombre es ajeno a la compasión, entonces será menos y no más que hombre.

Por otra parte, no hay que hacer ningún esfuerzo especial para mostrar la conexión de lo que en efecto está conectado. Aun así, superar la trivialización y hablar de cuestiones de calado, a la luz de la relación humana entre dos personajes como éstos, no parece fácil. El lenguaje pierde su primitiva fluidez cuando nos confrontamos, a través de él, con la búsqueda de lo no manifiesto, sea en la propia lengua, sea en el mismo pensamiento que intenta representar lo ausente e invocar lo que tan sólo en forma espectral asoma de cuando en cuando a la realidad que cotidianamente habitamos.

Así, la prosa de Derrida está cargada de una añoranza de la que se deriva una buena dosis de energía positiva, pero también de frustración. El gozoso fluir que adopta en tantas ocasiones apenas puede ocultar las ausencias, los silencios, los miedos del niño que no quiere cerrar los ojos pues teme lo que verá con claridad al cerrarlos. Aquello que hemos aprendido a temer en la infancia, seguirá atemorizándonos toda la vida. El horror puede quedar sometido a otro régimen, tener otros desencadenantes, pero su raíz sigue llamando al niño que fuimos y que nunca dejaremos de ser. 
Apprendre à vivre enfin ${ }^{1}$ es un texto que recoge las respuestas de Jacques Derrida a Jean Birnbaum que, en versión resumida, fue publicado en el periódico Le Monde el 19 de agosto de 2004. Es una obra que impresionaría en cualquier caso, pero mucho más cuando pensamos que Derrida respondió a ese cuestionario cuando la vida se le escapaba. Aunque parezca una afirmación desmesurada, creo que es mucho lo que nos puede ayudar lo manifestado por este gran pensador en la más difícil e inacabable tarea del ser humano, que no es otra que la de aprender a vivir. El título que se dio a la entrevista, en la versión de la misma publicada en Le Monde, "Je suis en guerre contre moi-même»" , es en realidad una frase extraída de las respuestas de Derrida a su entrevistador. Algunas de sus reflexiones pueden ayudarnos a comprender las razones de esa lucha contra sí mismo. En efecto, considera que aprender a vivir ha sido sobre todo aprender a morir y confiesa que nunca ha aceptado la muerte. A su juicio, en contra de lo establecido desde el núcleo mismo de una larga tradición, filosofar no ha de ser aprender a morir, sino aprender a vivir. Bien es cierto que, como él mismo considera, somos supervivientes en situación de libertad bajo fianza, pero eso no debe conllevar la renuncia a apurar la vida que tenemos hasta el último sorbo. Éste sería uno de los elementos conclusivos de la entrevista y su significado va mucho más allá del tópico en el sentido que le otorga Derrida.

\section{Aproximaciones desde la estética. El concepto de obra}

Aunque pueda parecer paradójico, Nietzsche —que, pese a lo dicho hasta aquí, ha influido de forma decisiva en la formación y orientación del pensamiento de Derrida ${ }^{3}$ - es un defensor de los parámetros del modelo clásico en el arte, representado por el clasicismo francés del siglo XVII, frente al interés romántico, que él consideraba «reactivo». Nosotros podemos considerar el trasfondo de su planteamiento aludiendo a una interpretación que puede resultar chocante, pues conduce a concluir que lo reaccionario en el arte es todo aquello que queda devorado por la actualidad.

Luc Ferry subraya esta idea en Homo Aestheticus, aunque basta oír la música que Nietzsche compuso para convencerse de su gusto clásico. Este autor recurre a una exégesis de sus escritos sobre estética para demostrar su tesis. Pero, ¿qué significa hoy lo clásico?

Quizá, para captar el significado de lo clásico, habría que volver al momento anterior a las vanguardias aunque en el momento actual, para muchos intérpretes, tal vez lo clásico o lo más asimilable a lo que hemos considerado clásico hasta aquí sea la vanguardia misma. El problema estético no tiene, en todo

1 DERrida, J., Apprendre à vivre enfin, Paris, Galilee, 2005.

2 «Estoy en guerra contra mí mismo».

3 Derrida, J., Éperons, les styles de Nietzsche, Paris, Flammarion, 1978, pp. 27 y ss. 
caso, solución en nuestro tiempo. Pero esto es así porque no tiene una solución, ni falta que hace que la tenga. El arte define cada día sus parámetros y lo que podemos asimilar al concepto de vanguardia en la actualidad es aquello que rompe con la continuidad establecida por las vanguardias clásicas entre arte y política.

Hoy el arte es negación de lo político y afirmación, al propio tiempo, de la raíz misma de lo político. La posibilidad de establecer nuevas y sólidas bases para la convivencia y la posibilidad de encauzar la violencia, pasan necesariamente en la actualidad por la creación artística, pero esa estética nueva nace o tiene una de sus fuentes en el rechazo de la política actual, que es indiferenciada en su trasfondo ideológico y a la vez legitimadora de las diferencias radicales que existen y persisten.

Un efecto esclarecedor pueden tener, en relación a lo que acabo de plantear, estas palabras de Luis Cernuda sobre el impacto que en su conciencia infantil produjo su primer contacto con la narración mitológica.

Bien temprano en la vida, antes de que leyeses versos algunos, cayó en tus manos un libro de mitología. Aquellas páginas te revelaron un mundo donde la poesía, vivificándolo como la llama al leño, transmutaba lo real. Qué triste te pareció entonces tu propia religión. Tú no discutías ésta, ni la ponías en duda, cosa difícil para un niño; mas en tus creencias hondas y arraigadas se insinuó, si no una objeción racional, el presentimiento de una alegría ausente. ¿Por qué se te enseñaba a doblegar la cabeza ante el sufrimiento divinizado, cuando en otro tiempo los hombres fueron tan felices como para adorar, en su plenitud trágica, la hermosura? ${ }^{4}$

En el caso de Cernuda, el contacto con la mitología le sirvió para reafirmarse en su deseo de rebeldía, tanto en lo que en su existir ha de juzgarse desde un ángulo ético como en todo lo que supone un compromiso estético. Le impulsó a luchar por ser quien era. En esa misma línea, a Nietzsche tal contacto le produjo un efecto aún más devastador, pues le condujo a un cuestionamiento total de los presupuestos religiosos, morales y epistémicos en los que se había basado su esfuerzo de integración personal en el mundo en que le tocó vivir. En él, el antisemitismo desempeñaba una función crucial. Por ello es inevitable abordar la relación de Nietzsche con esa ideología que condujo a una atroz persecución y a una horrenda política de exterminio de los judíos en Europa. Al respecto, Sarah Kofman, en Le mépris des juifs. Nietzsche, les juifs, l'antisémitisme, se expresa en los siguientes términos.

Son conocidas las falsificaciones efectuadas por su hermana Elisabeth Foster, que se convirtió en la directora de los archivos Nietzsche en Weimar y fue considerada como la portavoz y la intérprete autorizada de su filosofía. Su antisemitismo y el de su marido son notorios, como también su amistad con Hitler y Mussolini (éste último había leído todos los libros de Nietzsche). Partidaria declarada del nazismo, en su 88 cumpleaños recibió a Hitler a la

4 Cernuda, L., «El poeta y los mitos», en Cernuda, L., Ocnos, Madrid, El País, 2003, p. 34. 
entrada de los archivos en Weimar, encuentro inmortalizado por una fotografía histórica no menos célebre que aquella de Hitler posando ante el busto del filósofo en 1934. En los funerales — casi nacionales - de Elisabeth, el Führer en persona depositó una corona de laurel sobre el ataúd. Dos años después de su muerte, gracias al comandante Ehler, su primo y colaborador en los archivos, se inauguró, en presencia de altos funcionarios nazis, un monumento conmemorativo del filósofo (Musolini ofreció para la ocasión una estatua de Dionisos). Hitler había concebido este proyecto en 1935. ¡Él quería dotar el monumento de un auditorio y una biblioteca, y convertirlo en un lugar de encuentro para la juventud alemana que podría seguir allí seminarios, conferencias y talleres de estudio en los que se difundiría la supuesta doctrina nietzscheana de la raza superior! ${ }^{5}$

Sin embargo, pese al descarado interés del nazismo por apropiarse de la figura y el pensamiento del filósofo, lo cierto es que los reproches que éste realiza en relación a las raíces judías de la cultura occidental no conllevan una paralela actitud antisemita en el sentido del cuestionamiento, el rechazo y la persecución de un grupo humano como el judío, por imperativos racistas. En efecto, "Nietzsche deplora claramente haber sido malentendido por los alemanes del Reich, en particular en Ecce Homo, no se hace a sí mismo el honor de convertirse en su mayor halagador. Son los alemanes y no los judíos los que forman parte de sus imposibles y se sitúan, desde el punto de vista tipológico, en sus antípodas: canallas carentes del sentido de la sutileza y la distinción» ${ }^{6}$.

Por el contrario, como bien señala Sara Kofmann, el filósofo alemán valora de forma encarecida algunos aspectos de la cultura judía. Así, «es el convertirse en señor del judío - y su conversión en noble y gran hombre- a partir de y gracias a su situación inicial y ancestral de servidumbre; es ésta inversión casi hegeliana de la servidumbre en señorío lo que Nietzsche analiza con la mayor precisión y júbilo en el parágrafo 205 de Aurora ${ }^{7}$. Este aspecto que destaca Kofmann nos proporciona un sólido punto de apoyo para contestar la adscripción interesada de Nietzsche a la ideología del nacionalsocialismo.

\section{EL NOMBRE PROPIO}

En «Politiques du nom propre. L'enseignement de Nietzsche», Derrida comienza hablando de un pasaje de Así habló Zaratustra, que se titula «De la redención». En él menciona Nietzsche a un hombre-oreja, señalando que camina entre los humanos como si lo hiciera entre fragmentos de hombres y no entre seres humanos completos. El vitalismo nietzscheano se enfrenta de ése y otros

5 Kofman, S., Le mépris des juifs. Nietzsche, les juifs, l'antisémitisme, Paris, Galilée, 1994, p. 13.

6 Ibídem, pp. 14-5.

7 Ibídem, p. 44.

Nietzsche, F., Aurora, Barcelona, J. J. Olañeta, 1981, pp. 118-120. 
modos a la tendencia a la fragmentación de lo real, procedente de la metodología científica que ha hecho de la tecnociencia un factor determinante en el desarrollo del dominio humano sobre lo social y lo natural. En ese contexto, «la vida deviene muy difícilmente objeto de la ciencia, en el sentido que la filosofía y la ciencia han dado siempre a esa palabra, así como en lo que se refiere al estatuto moral de la cientificidad» ${ }^{8}$.

En este trabajo, «Politiques du nom propre», plantea Derrida su lectura de Nietzsche partiendo de Ecce Homo. Es decir, de una obra en la que el autor pone su ser y su nombre en primer plano, desde el principio'. En el prefacio de la misma, el pensador alemán escribe unas palabras conmovedoras por su autenticidad, tan alejada de toda retórica: «me parece indispensable decir aquí quien soy».

Es preciso señalar la dificultad de situar y comprender ese acontecimiento que tiene que ver con el momento en que Nietzsche ve su propia vida como un don y se plantea la necesidad de dar cuenta de ella, de explicarla al lector al propio tiempo que se la explica a sí mismo ${ }^{10}$. Tal acontecimiento sucede cuando Nietzsche cumple 45 años. Podemos situar ese momento en el período de redacción de Ecce Homo, obra en la que se registra esa experiencia. Pero habría que detenerse a hablar del nacimiento de Nietzsche, de la peculiar mezcla de vida y muerte que él mismo detecta en su origen. Al abordar esta cuestión Derrida habla de «double naissance» ${ }^{11}$.

Nietzsche dice en Ecce Homo, y Derrida lo recoge en su texto, concediendo a esas palabras la relevancia que merecen, que "para poder comprender la mínima cosa de mi Zaratustra, uno debe quizá encontrarse en una condición vecina a donde yo estoy — con un pie más allá de la vida». Al respecto, afirma Derrida: «Un pie, y más allá de la oposición entre la vida y/o la muerte, un solo paso» ${ }^{12}$.

Señala asimismo que «hay una différance de la autobiografía», a través de ella se marca un punto crucial a partir del cual la autobiografía puede interpretarse como tanatografía, o bien devenir narración de la propia vida como si fuese la vida de otro. Para Derrida, «en esta différance se enuncia justamente de nuevo la cuestión de la institución de enseñanza $»^{13}$, ya que ésta contiene la referencia más trascendente que puede hacerse al poder que las instituciones tienen de conformar y transformar a los individuos.

Un aspecto esencial es el que se refiere a la lengua, a su aprendizaje como molde del espíritu individual y estructura de identificación con la colectividad. En ese sentido, afirma que «hay, por tanto, una ley. Ésta crea una obligación

8 Derrida, J., « Politiques du nom propre. L'enseignement de Nietzsche », en Levesoue, C. - Mc Donald, Ch. V. (Dirs.), L'oreille de l'autre, Montréal, VLB, 1982, p. 17.

9 Ibídem, p. 19.

10 Ibídem, pp. 25-6.

11 Ibídem, p. 29.

12 Ibídem, p. 32.

13 Ibídem, p. 33. 
en relación a la lengua y, en particular, en relación a la lengua en la que se expresa la ley, la lengua materna» ${ }^{14}$. De ahí que la relación con la lengua afecte en lo más profundo a la relación del individuo consigo mismo. Pues, «con la lengua viva, la lengua del viviente, debe haber un contrato y una alianza contra la muerte. Y como el contrato, el hymen, la alianza, la afirmación reiterada, pertenece siempre a la lengua, revierte sobre la marca de la lengua materna, no degenerada, noble» ${ }^{15}$.

Derrida opone en Nietzsche la lengua materna, el alemán, que fue para él la lengua de la vida, a la lengua paterna, que era el latín, pues su padre era pastor luterano. Él considera ésta última como lengua de la muerte, al relacionarla con el fallecimiento prematuro de su padre y vincularla además con la represión de los impulsos vitalistas, a su juicio propia de la cultura que se ha construido sobre la influencia cristiana ${ }^{16}$.

Derrida comenta asimismo el texto de Nietzsche, «El porvenir de nuestros establecimientos educativos» y se pregunta cómo ha sido posible la falsificación que ha vinculado a Nietzsche con el nazismo. No obstante, esto no le impide acabar diciendo que habría que preguntarse también por qué el único sistema educativo que se ha reclamado seguidor de las ideas de Nietzsche ha sido el nazi ${ }^{17}$. Preguntas a las que él prefiere no responder, pero que dejan en el aire un halo inquietante.

\section{Pensar ES Decir NO}

En los archivos Derrida, conservados en el IMEC, encontramos toda la documentación relacionada con el curso que impartió en la Universidad de la Sorbona, bajo el título "Pensar es decir no». En sus apuntes comienza haciendo un planteamiento epistemológico, para adentrarse luego en un terreno lleno de peligros en el que se mezclan lo religioso, lo ético y lo político. Uno de los principales referentes del curso es Alain, a quien pertenece por cierto la frase que da título al mismo ${ }^{18}$. También hay referencias a Platón, en particular al diálogo Gorgias, más en concreto a la discusión que en él aparece acerca de la naturaleza del Bien ${ }^{19}$. El carácter absoluto del mismo, que Platón le atribuye para evitar su disolución en el perpetuo conflicto de opiniones que se da en la sociedad, constituye el mayor obstáculo a la concreción real del bien en la vida social. Una cierta dosis de frivolidad sería imprescindible para traer la idea de bien desde el Cosmos noetós al mundo real.

\footnotetext{
14 Ibídem, p. 35.

15 Ibídem, p. 36.

16 Ibídem, pp. 35-36.

17 Ibídem, p. 39.

18 Alain, Propos sur les pouvoirs, Paris, Gallimard, 1985, p. 351.

19 Derrida, J., Penser c'est dire non. Sorbonne, 60-61. IMEC-ARCHIVES, DRR 160.
} 
En ese sentido, en su obra La arqueología de lo frívolo, señala Derrida que «la ciencia debe curar, en sentido transitivo e intransitivo de este término, la ciencia debe curar (de) la ciencia ${ }^{20}$. En efecto, la ciencia debe curarse a sí misma, protegerse y protegernos de sus excesos. Así pues, nada puede haber más serio que esa forma de frivolidad.

Un aspecto al que es ineludible referirse al aproximarnos al pensamiento de Derrida es el de la explicación del significado de la deconstrucción, término que define en buena medida la tarea que él asumió como filósofo. En Puntos suspensivos, afirma a propósito de la deconstrucción que

deconstruir es un gesto a la vez estructuralista y antiestructuralista: se desmonta una edificación, un artefacto, para hacer aparecer las estructuras, las nervaduras o el esqueleto, como usted decía, pero también, simultáneamente, la precariedad ruinosa de una estructura formal que no explicaba nada, no siendo ni un centro ni un principio, ni una fuerza ni siquiera la ley de los acontecimientos, en el sentido más general de esta palabra.

La deconstrucción como tal no se reduce ni a un método ni a un análisis (reducción a lo simple); va más allá de la decisión crítica misma. Por ello no es negativa aunque a menudo sea, a pesar de tantas precauciones, interpretada así. Para mí, va acompaña siempre una exigencia afirmativa, diría incluso que no se realiza jamás sin amor ${ }^{21}$.

La tarea de la deconstrucción no es equiparable a la acción que provoca una demolición. No debe, por tanto, interpretarse tan sólo en clave destructiva. Por el contrario, la deconstrucción es la condición básica de toda operación constructiva en el ámbito del conocimiento filosófico ${ }^{22}$. Derrida habla asimismo de la voluntad y el deseo de presencia, que puede interpretarse en términos escalares, pues se da en muy diversos niveles y formas de la realidad. Su resistencia a ser eliminado podría calificarse de proverbial. En efecto, "¿cómo se dejaría destruir el deseo de presencia? Es el deseo mismo. Pero lo que le da, le da su respiración y su necesidad - lo que tiene y lo que queda en la presencia del presente no se presenta. La différance o la huella no se presenta, y ese casi nada ${ }^{23}$ de lo impresentable, los filósofos intentan siempre borrarlo. Es sin embargo esta huella lo que marca y relanza siempre los sistemas» ${ }^{24}$.

Sustituir la $e$ por la $a$, para construir el término différance, conlleva una operación que nos abre o intenta abrirnos a la posibilidad de pensar lo impensable. Esa operación nos aleja de todo el ámbito de lo previsible y lo claramente determinable sin recurrir a la analogía. No es tan sólo una operación de sustitución y mucho menos de borrado. Para él, «el borrado no es simplemente

20 Derrida, J., L'archeologie du frivole, Paris, Galilee, 1990, p. 20.

21 Derrida, J., Points de suspension, Paris, Galilee, 1992, pp. 88-9.

22 Fernández Agis, D., Mucho más que palabras. Discurso político y compromiso ético en Derrida y Lévinas, $2^{\mathrm{a}}$ edición, S/C de Tenerife, Hache Hache ediciones, 2018, pp. 183 y ss.

${ }^{23}$ «Presque rien». La expresión evoca la reflexión filosófica sobre aquello que es considerado «casi nada», realizada por V. Jankélévitch.

24 Derrida, J., Points de suspension, Paris, Galilee, 1992, p. 89. 
lo contrario de la inscripción. Se escribe con ceniza sobre cenizas. Y eso no solamente no es nihilista, sino que diría que la experiencia de la ceniza es lo que comunica con la experiencia del don, de lo no guardado, de la relación con el otro como interrupción de la economía. Esta experiencia de la ceniza es también la posibilidad de la relación con el otro, del don, de la afirmación, de la bendición, de la plegaria» ${ }^{25}$.

Gianni Vattimo, en su escrito «¿Hacia un crepúsculo de los valores?», afirma que

el error, si podemos hablar así, del joven Nietzsche y, más tarde, del Spengler de La decadencia de Occidente, fue pensar que el crepúsculo era algo negativo. Por una parte, no dudo en considerar su vitalismo como una expresión de la persistencia de lo que Heidegger ha llamado la metafísica y que un filósofo como Derrida llamaría el logocentrismo o, más precisamente, la dominación de la presencia o quizá el mito de la presencia, en tanto que plenitud del ser, en oposición al recuerdo, a la espera del futuro (la palabra crepúsculo significa no solamente el declinar del sol al ponerse, sino también la luz incierta que anuncia su alzarse), en resumen, a toda condición más espiritualizada que pretenda ser más verdadera que la verdad que se ve, se toca, se mide ${ }^{26}$.

Los planteamientos filosóficos, incluso aquellos que parecen ser más abstractos y alejados de la realidad, están marcados en su propia constitución por una vinculación específica con la misma. El compromiso del pensador no se ciñe a una estrecha vinculación con la palabra. Por eso, para él,

la metafísica en tanto que mito vitalista de la presencia plena (energeia), que no es solamente la evidencia sino también la energía, la fuerza y la resolución decisionista tan apreciada por los fascistas de todos los colores. La metafísica, según Heidegger y Nietzsche, no entra en crisis por razones teóricas, como si algún filósofo hubiese descubierto el principio de su error. Es por esto que la relación con el colonialismo y el imperialismo se vuelve a encontrar aquí en los términos simétricamente opuestos a los de Spengler.

La metafísica no se revela, ante todo, como un error: deviene imposible a causa de las transformaciones sociales y políticas que convierten en obsoleta una cierta visión de la Historia que en otros tiempos había legitimado a la propia metafísica y al imperialismo. Los pueblos terceros se rebelan y ganan su libertad —no siendo ésta una donación teórica, sino realizándose como un hecho- buscando el contexto de la experiencia en el que la filosofía se formula. No olvidemos a Napoleón a caballo delante de Jena, visto por Hegel. La caída de la metafísica se hace no sólo posible sino necesaria por la liberación de los antiguos pueblos colonizados ${ }^{27}$.

Por tanto, si algo caracteriza a lo humano, en términos generales, es la marca del tiempo sobre cada una de sus creaciones, el peso de la historia sobre

25 Ibídem, p. 233.

26 VAтtimo, G., «Vers un crépuscule des valeurs?», en Bindé, J. (Dir.), Où vont les valeurs?, Paris, UNESCO - Albin Michel, 2004, p. 32.

27 Ibídem, p. 33. 
cada uno de los aspectos de la vida. En ella las mentiras se convierten en los adoquines con los que está empedrada una interminable calzada. En eso radica, entre otros aspectos de menor relevancia, la frontera que marca la separación entre lo humano y lo animal. Así, refiriéndose a las Consideraciones intempestivas I y II, de Nietzsche, afirma Lippit que «el animal, para Nietzsche, es sincero porque vive de forma no histórica» ${ }^{28}$.

Nuestra historia se ha ido desplegando entre condicionantes culturales, pues éstos han tenido siempre un peso mayor que las constricciones ejercidas por el medio natural, que la humanidad ha ido sorteando con mayor o menor fortuna, teniendo siempre como horizonte su propio provecho. Uno de esos condicionantes naturales ha sido siempre el constituido por las creencias religiosas. En ese contexto ha hablado Derrida de la necesidad de «deconstruir el cristianismo». También de la larga tradición en torno a la concepción del pecado y de cómo llega ésta hasta Heidegger y Lévinas, en los que, antes de cometer cada cual cualquier falta, soy considerado como un ser que se caracteriza por la capacidad de contraer una «deuda». Por consiguiente, un ser en el que la condición de la existencia, en sí misma, se vincula tanto al pecado como a la expiación ${ }^{29}$.

Por su parte, Sloterdijk ha señalado que «el problema principal de la filosofía moral de nuestros días es la liberación del egotismo del Otro. Este fenómeno es conocido bajo el nombre de 'propaganda a favor de los derechos del hombre', una fórmula que tiene la ventaja de ser generalmente aceptable, pero que tiene el inconveniente de ocultar el sentido profundo, hablando sistémicamente, del egotismo del Otro ${ }^{30}$.

Para explicar su sorprendente postura, Sloterdijk afirma que «los desheredados de la tierra, es decir los que no tienen aún acceso a las delicias de esta forma de vida egoísta, deben beneficiarse de la ayuda de un abogado que los asista en sus demandas egoístas. Como este egoísmo ha sido siempre el enemigo principal de la filosofía moral occidental, una asistencia a las necesidades egoístas del otro es necesariamente una forma moderna de lo que la tradición ha denominado "el abogado del diablo" $»^{31}$.

Abundando en la caracterización de la figura del abogado del diablo y tratando de explicar por qué recurre a ella en su ensayo, nos dice Sloterdijk que

de la misma forma que en los procesos de santificación, el avocatus diaboli no tenía otra misión que hacer que resaltara, de una manera más brillante, la afirmación positiva del juicio final, el negativo moderno debía forzosamente

28 Lippit, A. M., «L'animal magnétique», en MaLlet, M. L. (Dir.), L'animal autobiographique, Paris, Galilée, 1999, p. 187.

29 Derrida, J.; NANCY, J.-L., «Responsabilité - du sens à venir», dans, Guibal, F.; Martin. J.-C. (Dirs.), Sens en tous sens. Autour des travaux de Jean-Luc Nancy, Paris, Galilée, 2004, p. 184.

30 SloterdiJK, P., «L'avocat du diable, entre l'éthique et la systémique», en Bindé, J. (Dir.), Où vont les valeurs?, Paris, UNESCO - Albin Michel, 2004, p. 65.

31 Ibídem, pp. 65-6. 
hacer sus comprobaciones como parte de esta farsa empleada con profusión en Alemania hasta un período reciente, que siempre quiere el mal y siempre crea el bien. Esta lógica ha persuadido de tal modo a un padre franciscano alemán contemporáneo que demandó en 1960, en el seno de la congregación de los ritos de la Santa Sede, un proceso de beatificación de Judas Iscariote, sin cuya fiel traición la pasión no hubiese tenido nunca lugar ${ }^{32}$.

Sloterdijk plantea que el intelectual moderno actúa frecuentemente como el abogado del diablo, en el proceso de defensa de los derechos del Otro. Pero dicho proceso no es en realidad sino el de la promesa y la defensa de las expectativas egoístas, según él lo interpreta. Aunque Sloterdijk consideraba que la clave es la promesa. Él tiene claro que Nietzsche pensaba que es de mucha mayor efectividad para la política o la religión prometer, aunque en el caso extremo lo prometido sea la nada, que dejar de formular promesas y basar su incentivo en ellas.

La escatología religiosa muestra tal vez así, como bajo un espejo aumentador, algo del estatuto de verdad de la promesa en general: no hace referencia a la verdad como correspondencia con un estado de cosas presente; la verdad de la promesa aparecerá cuando quede verificado que se ha mantenido la palabra, que se ha dicho la verdad. Estas mismas fórmulas inscriben el tiempo en la forma de verdad implicada por la promesa: el porvenir confirma la verdad del pasado, es decir, retroactivamente, desde el momento en que la promesa se ha emitido. La verdad de la promesa supone el tiempo, pero lo supone para resistirlo, para vencer el efecto de la pérdida, de la ruptura de los lazos, del olvido, de la anulación que puede conllevar el tiempo. De donde proviene, quizá, una afinidad profunda entre la forma de la promesa y el contenido escatológico, entre promesa y religión de la salvación; porque una promesa religiosa típica, es precisamente aquella que promete que algo resistirá al tiempo, a la pérdida, a la ruptura de los lazos y las alianzas, que algo resistirá a la muerte ${ }^{33}$.

Si nos referimos a las promesas que resisten al tiempo, habrá que hablar de escritura, pues la escritura es la más eficaz coartada contra el tiempo. Su práctica conlleva diversas estrategias de recuperación y reactualización de la experiencia vivida. En esas estrategias la forma en que se realiza la lectura de lo escrito tiene una importancia crucial. Es relevante tomar en consideración algunos aspectos relacionados con la gestación y evolución de la escritura en la civilización occidental, en particular en la tradición griega. Desde esta perspectiva resulta esclarecedor tener presente que

una de las tesis mayores de Svenbro es que la lectura en voz alta está inscrita en los textos de la Grecia antigua. Hace valer una observación técnica: los griegos escribían sin poner intervalos entre las palabras —en scriptio continua- y estaban por tanto prácticamente forzados a realizar la lectura en voz

32 Ibídem, p. 68.

33 Monod, J. C., «La promesse, entre religion et politique», en CréPon, M.; De LaunaY, M. (Dirs.), La Philosophie au risque de la promesse, Paris, Bayard, 2004, pp. 135-6. 
alta. Esta necesidad da al lector un estatuto particular: él es el instrumento indispensable para la realización del texto, debe ceder su voz al texto que se la apropia para ponerla a su servicio. La voz no puede entonces hacer otra cosa que seguir la huella escrita ${ }^{34}$.

En efecto, el lector hace de la huella reveladora de un camino. Con ello, no sólo rememora lo acaecido, sino que invita a los que escuchan la lectura a seguirlo hacia un nuevo acaecer. Podría decirse, yendo un poco más lejos, que «la lectura a voz alta genera la obediencia, si es verdad, como sostiene Svenbro, que para un griego escuchar —en particular el texto de la ley- es obedecer ${ }^{35}$. Aunque se exagere de esa forma el peso real sobre los otros del ejercicio de la lectura, es indudable que resulta

legítimo preguntarse qué factores explican el surgimiento de la lectura silenciosa en el mundo antiguo. Knox sugiere que la gran cantidad de textos leídos por una misma persona le abre la posibilidad de esta práctica silenciosa y más rápida. Para Svenbro, este único factor no es suficiente. Es preciso adelantar que la experiencia del teatro ha estructurado la lectura silenciosa. Svenbro conjetura que los griegos vivieron de forma análoga la separación entre la escena y el público, y la separación entre el escrito y el lector. En el teatro el público no puede intervenir en el juego ficticio al que asiste, debe solamente contemplar, mirar y escuchar en silencio, pasivamente. A la inversa de la lectura en voz alta que exige una actividad, a la vez intelectual, visual y vocal, la lectura silenciosa omite la voz del lector para no hacer apelación sino a la vista y al intelecto, quizá a la escucha interna. La voz lectora es interiorizada, el lector deviene espectador del teatro de la escritura ${ }^{36}$.

Platón recomienda en el Fedro que, si no queda otro remedio, se recurra a la escritura y luego, obviamente, a la lectura; pero que ésta se haga en voz alta. Preferentemente que sea otra persona distinta a la que ha escrito quien lea. A la luz de lo expuesto hace un momento, estas recomendaciones platónicas tienen una gran significación.

Interpretar se convierte entonces en desvelar lo no dicho del texto, en culminar o acabar un texto que está, sin embargo, ya completo.

El no dicho del texto es puesto en evidencia por numerosas parábolas, en su dimensión tanto espacial como temporal. Así puede encontrarse en la tradición cabalística la idea de que la Torá, en su existencia visible, contendría 340.000 letras, mientras que, de forma misteriosa, comprendería 600.000. Este número es el de los israelíes que salieron de Egipto, quienes han recibido cada uno la Torá. Cada individuo poseería una letra que no tendría ningún otro y que le permitiría leer el texto de forma singular. La espacialidad del texto no se limita, por tanto, a su materialidad visible. Lo mismo puede decirse por lo que respecta a su temporalidad. Los espacios en blanco de la Torá

34 Lisse, M., L'expérience de la lecture. Vol. I, La soumission, Paris, Galilée, 1998, p. 20.

Svenbro, J., Phrasikleia. Anthropologie de la lectura en Grèce ancienne, Paris, La Découverte, 1988.

35 Lisse, M., Op. Cit., p. 20.

36 Ibídem, p. 22. 
serían letras ilegibles hoy en día, en nuestro ciclo cósmico, en nuestra actual Schmitta, en el que no podemos leer nada más que el negro de las letras. Pero el blanco debería ser revelado por Dios en la época mesiánica ${ }^{37}$.

La revelación, sin embargo, de ser aceptada colectivamente como tal, puede otorgar un poder incontrolable a quien afirma ser su depositario. El dogmatismo religioso es la matriz generadora de otras formas de dogmatismo, cuya orientación es inevitablemente opresora. El islamismo radical es un triste ejemplo de ello, aunque no hay que olvidar que la tendencia dogmática aparece tarde o temprano en toda forma institucionalizada de creencia religiosa.

Adentrándose en ese espinoso asunto y hablando para ello de la problemática cuestión de la aceptación o no del velo islámico en Occidente, Derrida señala que toda referencia al velo puede provocar una peligrosa conmoción en nuestra cultura $^{38}$. Y añade, para explicar su prevención ante la mera enunciación de la palabra, que «el ejemplo o la muestra de la mortaja resume la esencia del velo» ${ }^{39}$. No deberíamos trivializar un debate que tiene un trasfondo tan dramático. Derrida escribe lo siguiente abundando en dicho trasfondo.

Hago como si me confesara: a falta de haber sabido demasiado bien lo que comienza a suceder de verdad con los velos en todas sus versiones, como si aparentemente la suerte de la humanidad, de la así llamada humanidad que habría nacido con el pudor, la retentiva, la Verhaltenheit, la desnudez, el saber mal, el saber el mal, el árbol del conocimiento, el pecado, la caída o la Verfallen, por tanto el velo, como si la suerte de la humanidad fuera aún a depender hoy en día de quien tiene el poder sobre las mujeres en lo que al velo se refiere. Y no hablo sólo de una interpretación abusiva del Corán. San Pablo no existió en vano, habrá que hablar de él, y lo que más admiro en Nietzsche es su lucidez en cuanto al papel de San $\mathrm{Pablo}^{40}$.

La cuestión de fondo sería, contra toda debilitada impresión inicial, «romper con este Uno sin dejar huellas, ni siquiera una traza de partida, ni siquiera la marca de una ruptura, he aquí la única decisión posible, he aquí el suicidio absoluto y el sentido original que puede haber en dejar vivir al otro, dejarlo ser, sin ni siquiera descontar el mínimo beneficio del velo o la mortaja ${ }^{41}$. Pero Derrida introduce otros matices cuando señala que

lo que se separa la lógica o la tópica del velo de la del chal, de ese chal llamado tallith, del tallith único hasta en el número de sus vértices, alas, franjas, en tantos detalles establecidos, es la diferencia del acontecimiento, la irreductible referencia al Uno, al Uno que no se multiplica nada más que la primera vez, y me da mi tallith a mí, a mí sólo, a la vez como el mandato y el don, incluso si yo no puedo y no debo nunca apropiármelo, asignándome a mí mi

37 Ibídem, pp. 150-1.

38 DerridA, J., «Un ver à soie. Points de vue piqués sur l'autre voile», dans Cixous, H.; Derrida, J., Voiles, Paris, Galilée, 1998, p. 27.

39 Ibídem, p. 35.

40 Ibídem, p. 42.

41 Ibídem, p. 43. 
ipseidad en lo que es estrictamente necesario llamar una historia, una sola historia. La unidad de esta referencia, el aspecto intraducible de esta referencia impide a un tallith, este del que no podemos ni debemos deshacernos, no ser o no devenir, como cada velo, sino una figura, un símbolo, un tropo. ¿Significa esto que la literalidad de tallith, el mío, es irreductible? ${ }^{42}$

Derrida acaba ese texto recordando cómo, de niño, criaba gusanos de seda en una caja de zapatos en El Biar (Argelia). Comenta cómo los vigilaba y alimentaba. De qué manera éstos elaboraban la seda, como una secreción, en respuesta al alimento que él les proporcionaba y cómo formaban los capullos de los que luego se obtiene la seda.

Podríamos pensar que introduce esta evocación al final de su escrito para recordarnos que con la seda se puede elaborar tanto un velo como un tallith; es decir, tanto algo que separa y unifica, como algo que sólo pertenece a un individuo y que está presente en su vida en el momento de recibir la bendición de su padre, cuando va a dejar de ser niño, y en el momento de la muerte.

Las dificultades del velamiento, la dificultad o imposibilidad, a veces, de la traducción, aluden a la gran cantidad de velos que nos impiden penetrar en otras culturas, intentar aprender una esencia inaprensible y tal vez inexistente, que no se debe perseguir, en todo caso. Ésta tan sólo debe ser evocada para hablar del esfuerzo infinito, de la tarea oscilante e inacabable de la traducción. Transitar de una lengua a otra, eliminar los velos cuando éstos se dejan eliminar, cuando ellos mismos quieren ser eliminados, bajados, tal vez guardados o dejados reposar sobre los hombros, revelando o desvelando la vida, preparando de algún modo que no alcanzamos a comprender, la muerte.

¿Quiere decir Derrida que no hay cultura que no posea sus propios velos? $¿$ Que no existe desvelamiento, que no hay otro desvelamiento posible que el deseado por quien porta el velo? Sí, esas parecen ser las ideas centrales, en un texto brillante, en el que no encontramos ni una afirmación ni una negación sin condiciones, porque éstas han de estar presentes, cuando la negación o la afirmación responden a la toma en consideración de los determinantes y condiciones implicados. No existe lo incondicionado. Derrida ha hablado de su gusto por lo indecidible, de su incurable interés por lo aporético. A ello podríamos añadir su titánico empeño por decir lo indecible. Pero también tendríamos que hablar del rechazo del proyecto mesiánico de alcanzar lo incondicionado. Un proyecto del que todavía Kant se hacía eco en su Crítica de la razón pura. Pensar lo incondicionado sería tanto como acomodar el pensamiento para realizar un trayecto que conduce al no-pensar. Por eso Nietzsche se planteó la tarea de pensar como lucha permanente contra unos correosos enemigos que jamás se desvanecen.

$42 \quad$ Ibídem, p. 71. 
4. LA POSIBILIDAD DE LO IMPOSIBLE

¿Por qué lo esperado no se hace presente sin más? Vivimos en ese tiempo prestado, que transcurre entre dos momentos sobre los que no tenemos ningún control. El primero de esos momentos está marcado en cada biografía individual a sangre y fuego. Se trata del momento en que tomamos conciencia de que la vida transcurre en dirección a lo irreparable, a su propia negación en cada ser, siendo ésta la condición necesaria de cualquier afirmación posible.

En el segundo se confirmarán las sospechas y se realizarán las amenazas. Nada nuevo puede aparecer que esos momentos cambie. El sinsentido del sentido está establecido a partir de ellos. Sin embargo, la esperanza de algo diferente, de una espectral presencia que alumbre otra dirección, que abra otro camino, está latiendo de forma constante. Late en nuestro interior mientras negamos su latir moviendo la cabeza.

Los seres humanos hemos hecho grandes cosas cuando hemos conseguido movernos al ritmo de ese latido. Aunque, al final, bien sabemos que el latido no conformará una verdadera melodía antes de su inevitable cese. No es la vida la que se nos escapa, es el sueño de la afirmación el que no llegaremos a soñar. Vacuidad y vanidad en la distancia del espectro, en el no mirar hacia él ni dejarnos apoyar por su fugaz aparecer.

El espectro no está vivo, pero tampoco está muerto. Espera el momento en que asomar. No podremos verlo ni oírlo si creemos que nada es ya para nosotros, que todo en él pertenece al ámbito de la muerte, del que nadie puede salir. Él no puede escapar del ámbito de la muerte, es cierto, pero puede rozar la vida y manifestarse de nuevo en cada aproximación nuestra, en cada lectura en profundidad.

Se adueña de nuestro temor y juega a través de él su juego de aparición y desaparición. Así suena la voz de los maestros, como un eco espectral. Derrida oyó de esa manera las voces de Nietzsche, Husserl, Heidegger y otros maestros del pensamiento, con más claridad que la de cualquiera de sus contemporáneos. Su ventaja fue una actitud que tenía bien aprendida desde la infancia. Una predisposición que privilegiaba el escuchar y que le abría los ojos a la posibilidad de lo imposible.

Sin duda esto lo aprendió de niño, meditando tal vez en la oscuridad de su habitación. Hay una sencilla apertura al otro en su manera de dar rienda suelta a su búsqueda. Abordando cuestiones que producen la impresión de una aproximación a lo periférico, de un pensar que no elude el peso del sueño del pensar. El sueño del pensar no es el sueño de la razón, pero también suscita la aparición de goyescos monstruos. El espectro se presenta de nuevo ante quienes esperan y temen, ante los que quieren retener o recuperar algo de esperanza más allá del temor. 


\section{CONCLUSIÓN}

Nietzsche y Baudelaire construyen cada uno de ellos una obra en la que se modula el ambiguo sentir del intelectual moderno ante los cambios de los que, a lo largo de su vida, puede ser testigo. Construyen, en consecuencia, dos aproximaciones críticas a la modernidad. Por su parte, Derrida desarrolla su pensamiento en un espacio crítico que no habría aparecido sin esas dos aportaciones, la del filósofo artista y la del artista filósofo.

En su paradigmático texto, "Chacun sa chimère», Charles Baudelaire relata una singular visión en la que se presenta ante sus ojos un grupo de seres humanos que portan cada uno de ellos sobre su espalda un ser monstruoso, una horrible quimera. El poeta dice que interrogó a uno de ellos, pidiéndole que le dijese hacia dónde se dirigían.

Él me respondió que no sabía nada, ni él ni los demás; pero que, evidentemente iban a algún sitio, puesto que estaban impulsados por un invencible deseo de caminar.

Una cosa curiosa que hay que señalar: ninguno de estos viajeros tenía el aspecto de estar irritado contra la bestia feroz suspendida de su cuello y adosada a su espalda; se diría que la consideraba como si formase parte de él mismo. Todos estos rostros fatigados y serios no testimoniaban ninguna desesperación; bajo la cúpula spleenitica del cielo, con los pies hundidos en el polvo de un suelo tan desolado como ese cielo, caminaban con el aspecto resignado de los que están condenados por siempre a esperar ${ }^{43}$.

Finalmente recaerá en la desazón y concluirá diciendo: «durante algunos instantes me obstiné en entender este misterio; pero pronto, la irresistible Indiferencia se abatió sobre mí, y me quedé más pesadamente oprimido de lo que ellos mismos estaban por sus aplastantes Quimeras» ${ }^{44}$. De esta forma Baudelaire, al que tanto repugnaba la cotidianeidad que defendía frente a ella la pertinencia de una ebriedad permanente, acaba reconociendo que la falta de motivos para el compromiso ejerce sobre él un peso tan aplastante como el de las quimeras que los otros llevan sobre sí.

El poema recuerda a cualquier lector de Nietzsche la analogía del camello en Así habló Zaratustra. No obstante, la quimera es ilusión, falsa imagen creada en virtud de la fuerza que puedan tener los deseos. No sólo será carga, peso que el individuo lleva sobre sus hombros, sino también energía utópica, impulso irracional hacia algún objetivo. Por tanto, en ella se da la paradoja del simultáneo y permanente lastramiento que, sin embargo, va acompañado de cierta energía que puede servir de fuerza de impulso. Lo más negativo es ceder y quedar aplastado bajo el peso de la indiferencia.

43 Baudelaire, Ch., "Chacun sa chimère», en Baudelaire, Ch., Petits poèmes en prose (Le Spleen de Paris), Paris, Pocket, 1995, pp. 35-36.

44 Ibídem, p. 36. 
Es preciso, pues, evocar ese conocido capítulo de Así habló Zaratustra, que su autor tituló «De las tres transformaciones». Recordemos que esta obra se escribió entre 1883 y 1885, publicándose éste último año en una edición privada de 40 ejemplares, que Nietzsche repartió entre sus amistades. La primera edición comercial se realizó en 1892. Por su parte, los textos que componen la obra de Baudelaire se redactaron entre 1855 y 1864. Se fueron publicando en distintas revistas. No obstante, la obra fue publicada en 1869, tras la muerte de su autor.

No sabemos si el poema de Baudelaire influyó en Nietzsche a la hora de abordar la redacción del pasaje de Así habló Zaratustra, que tanta semejanza tiene con él ${ }^{45}$. Sí conocemos la admiración que sentía por Baudelaire, un autor al que Nietzsche leía apasionadamente en Niza, durante sus últimos días de lucidez y del que pensaba que acabaría teniendo una influencia decisiva en la cultura de su época, como así sucedió. En todo caso, existe una profunda sintonía entre los planteamientos de uno y otro. La escritura de Derrida, de forma consciente o no, parece estar marcada por la interacción de dos grandes impulsos, que me atrevería a decir que provienen de las respectivas aportaciones de Nietzsche y Baudelaire.

Resulta pertinente recordar aquí una afirmación que define una de las tomas de posición radicales de Derrida, que tan próxima resulta ser de la nietzscheana: «Lo que nos ha perdido es la verdad, ese horrible fantasma, el mismo que el del niño, finalmente ${ }^{46}$. Aunque más iluminador resultaría completar este diagnóstico, en la línea foucaultiana, con una reflexión acerca del poder que está a la base de la construcción de la verdad y que, a partir de ella, se fortifica y ejerce ${ }^{47}$.

En todo caso, Derrida añade unas interesantes reflexiones a propósito de lo espectral.

Fantasma nombra también para los griegos la aparición del espectro, la visión del fantasma o el fenómeno del que regresa de la muerte. Pero lo fabuloso y lo fantasmagórico tienen un trazo en común: stricto sensu, en el sentido clásico y prevalente de estos términos, no provienen ni de lo verdadero ni de lo falso, ni de lo veraz ni de lo mentiroso. Pertenecen más bien a una especie irreductible del simulacro, o quizá de la simulación, en el fenómeno de una virtualidad: ni ser ni nada, ni incluso un posible al que una ontología o una mimetología podría rendir cuenta o tener razón. No más que el mito, la fábula o el fantasma no son sin duda verdades o enunciados verdaderos como tales. Pero no son tampoco errores, engaños, falsos testimonios o perjurios ${ }^{48}$.

45 Nietzsche, F., Así habló Zaratustra, Madrid, Alianza, 1998, pp. 49 y ss.

46 DerRidA, J., La carte postale, Paris, Flammarion, 1980, p. 52.

47 Foucault, M., «Verdad y poder», en Foucault, M., Microfísica del poder, Madrid, La Piqueta, 1980, pp. 175 y ss.

48 Derrida, J., "Histoire du mensonge », en VVAA, Derrida, Paris, Cahier de L'Herne, 2004, p. 495. 
Aquí tenemos un excelente ejemplo del terreno que Derrida se ha dedicado a explorar. Un terreno ajeno a muchos de los temas característicos de la filosofía tradicional, pero sin embargo lleno de interés y casi virgen para la investigación. Entre lo uno y lo otro, previamente definidos y explorados, aún quedaba (y queda) mucho por pensar.

Derrida hace que quien lo sigue se sienta interlocutor suyo, que escuche su palabra y pueda responder a la misma. Hay en su obra una incitación constante a la discusión. Al leer sus escritos, lo imaginamos esperando una objeción, un comentario, una palabra que le haga esforzarse en reconsiderar su postura y afanarse en la búsqueda de otra respuesta. Por eso se presenta ante nosotros como un Genio Benigno, un espectro estimulante y esperanzador.

Nos invita a pensar que nunca se da la respuesta definitiva. El sueño del filósofo es un diálogo lo suficientemente comprometedor como para desestabilizar a quienes participan en él y proyectarse en el tiempo sobre esa inquietante base. El sueño compartido por quienes se apasionan por la filosofía es que no sea el silencio sino el eco indefinido lo que indique un cierto final. Bien es verdad que la dispersión de los ecos no señala un final tajante pero, en filosofía, es lo más parecido a un final. No olvidemos lo que escribió Nietzsche en, Humano, demasiado humano. En efecto, como él afirmó allí, «cuando nos transformamos intensamente, nuestros amigos que no han cambiado se convierten en fantasmas de nuestro propio pasado: el sonido de sus voces nos llega de forma espantosamente espectral, como si nos oyéramos a nosotros mismos, pero más jóvenes, más duros, menos maduros». Derrida, fundiendo su voz con la de Niezsche, cita este pasaje en Políticas de la amistad ${ }^{49}$. No sabría acabar de mejor manera este breve ensayo.

\section{BiBLIOGRAFÍA}

Alain (1985). Propos sur les pouvoirs. Paris: Gallimard.

Baudelaire, Ch. (1995). Petits poèmes en prose (Le Spleen de Paris). Paris: Pocket. Cernuda, L. (2003). «El poeta y los mitos», en Cernuda, L., Ocnos. Madrid: El País. Derrida, J. (2005). Apprendre à vivre enfin. Paris: Galilee.

Derrida, J. (1978). Éperons, les styles de Nietzsche. Paris: Flammarion.

Derrida, J. (1982). «Politiques du nom propre. L'enseignement de Nietzsche », en Levesque, C.; Mc Donald, Ch. V. (Dirs.), L'oreille de l'autre. Montréal: VLB,.

Derrida, J., Penser c'est dire non. Sorbonne, 60-61. IMEC-ARCHIVES, DRR 160.

Derrida, J. (1990). L'archeologie du frivole. Paris: Galilee.

Derrida, J. (1992). Points de suspension. Paris: Galilee.

Derrida, J.; Nancy, J.-L. (2004). «Responsabilité - du sens à venir», dans, Guibal, F.; Martin. J.-C. (Dirs.), Sens en tous sens. Autour des travaux de Jean-Luc Nancy. Paris: Galilée.

49 Derrida, J., Politiques de l'amitié, Paris, Galilée, 1994, p. 91. 
Derrida, J. (1998). «Un ver à soie. Points de vue piqués sur l'autre voile», dans Cixous, H.; Derrida, J., Voiles. Paris: Galilée.

Derrida, J. (1980). La carte postale. Paris: Flammarion.

Derrida, J. (2004). «Histoire du mensonge », en VVAA, Derrida. Paris: Cahier de L'Herne.

Derrida, J. (1994). Politiques de l'amitié. Paris: Galilée.

Fernández Agis, D. (2018). Mucho más que palabras. Discurso político y compromiso ético en Derrida y Lévinas, $2^{a}$ edición. S/C de Tenerife: Hache Hache ediciones.

Foucault, M. (1980). «Verdad y poder», en Foucault, M., Microfísica del poder. Madrid: La Piqueta.

Kofman, S. (1994). Le mépris des juifs. Nietzsche, les juifs, l'antisémitisme. Paris: Galilée.

Lippit, A. M. (1999). «L'animal magnétique», en Mallet, M. L. (Dir.), L'animal autobiographique. Paris: Galilée.

Lisse, M. (1998). L'expérience de la lecture. Vol. I, La soumission. Paris: Galilée.

Monod, J. C. (2004). «La promesse, entre religión et politique», en Crépon, M.; De Launay, M. (Dirs.), La Philosophie au risque de la promesse. Paris: Bayard.

Nietzsche, F. (1981). Aurora. Barcelona: J. J. Olañeta.

Nietzsche, F. (1998). Así habló Zaratustra. Madrid: Alianza.

Nietzsche, F. (1995). La Gaya Ciencia. Madrid: Alianza.

Sloterdijk, P. (2004). «L'avocat du diable, entre l'éthique et la systémique», en Bindé, J. (Dir.), Où vont les valeurs?.Paris: UNESCO - Albin Michel.

Svenbro, J. (1988). Phrasikleia. Anthropologie de la lectura en Grèce ancienne. Paris: La Découverte.

Vattimo, G. (2004). «Vers un crépuscule des valeurs?», en Bindé, J. (Dir.), Où vont les valeurs?. Paris: UNESCO - Albin Michel.

Universidad de La Laguna (Sta. Cruz de Tenerife)

Domingo Fernández Agis

dferagi@ull.edu.es

[Artículo aprobado para publicación en enero de 2019] 